OPEN ACCESS

Edited by:

Trine Fink,

Aalborg University, Denmark

Reviewed by:

Mohammad Abdul Baseer, Riyadh Elm University, Saudi Arabia

Angga Kautsar,

Universitas Padjadjaran, Indonesia

*Correspondence:

Mohamed N. Al-Arif

malarifi@ksu.edu.sa

Specialty section

This article was submitted to

Public Health Education and

Promotion,

a section of the journa

Frontiers in Public Health

Received: 30 August 2021 Accepted: 02 November 2021

Published: 06 December 2021

Citation:

Al-Arifi MN (2021) Assessment of Knowledge, Attitudes, and Factors Influencing the Selection Student of

Generic Medicine.

Front. Public Health 9:767128.

doi: 10.3389/fpubh.2021.767128

\section{Assessment of Knowledge, Attitudes, and Factors Influencing the Selection Student of Generic Medicine}

\author{
Mohamed N. Al-Arifi* \\ Clinical Pharmacy Department, College of Pharmacy, King Saud University, Riyadh, Saudi Arabia
}

Background: Generic replacements for branded medicines have become a typical practice among registered pharmacists all over the world. Therefore, this study was aimed to determine the influence of the knowledge and attitudes of PharmD students and other factors on the selection of unbranded medicines.

Methods: A descriptive, cross-sectional study was conducted through Google Forms to collect data using self-reported questionnaires. The data was collected over a period of 3 months, from January to March 2021, among junior level pharmacy students who are currently undertaking a PharmD course at the King Saud University, College of Pharmacy, Riyadh, Saudi Arabia.

Results: The mean age of the students was $21.05 \pm(S D=1.03)$, majority of students $70.2 \%(n=134)$ were able to define the term generic medicine, and about $65 \%(n=123)$ were able to correctly define bioequivalence. More than half of the students, $56.5 \%$ $(n=108)$ lacked knowledge about the pharmacokinetic parameters of generic products. Meanwhile, the majority, $85 \%(n=122)$, supported generics over branded medicines, and about $66 \%(n=99)$ agreed that wider use of generic medicines would lead to less money required for the research and development of new pharmaceuticals.

Conclusion: Findings revealed that most pharmacy students possess sufficient knowledge of generic medicines, although knowledge in some aspects remains lacking.

Keywords: generic drugs, knowledge, attitudes, factors, pharmacokinetic, bioequivalence

\section{BACKGROUND}

With advanced healthcare, costs are on the rise, including the cost of pharmaceuticals $(1,2)$. Consumption of drugs has been identified to be a large factor in the increasing costs of medical services, although evidence suggested that generic replacements for branded medicines have become a typical practice among registered pharmacists all over the world (3-5). Generic drugs are pharmaceutical products that are bioequivalent to branded drugs in both physical and chemical qualities (6-8). The estimated global spending on drugs is expected to exceed USD 1.5 trillion by 2023 (9). However, reports revealed that the estimated Saudi pharmaceutical expenditures are closer to USD 8 billion (9-11). Despite the supply and demand of drugs in the market, the prevalence of 
communicable and non-communicable diseases have become increasingly worldwide, and Saudi Arabia is not an exemption, which in turn increases the medicine expenditure cost to the patient and health care system (9-11). According to recent estimates, $\sim 18.5 \%$ of the population over the age of 20 is disabled, $35 \%$ is obese, and over $23 \%$ has hypertension. The Saudi Arabian healthcare burden has been noted to rise at a rapid rate in recent years, and it is expected to grow even further (9-11). However, more initiatives and investments have begun in recent years to stimulate pharmaceutical products as part of a strategic plan to produce at least $40 \%$ of all medicines locally in the long term $(12,13)$.

Multiple reports revealed that the use of generic drugs in comparison to branded medicines has allowed patients to save money without compromising healthcare quality $(8,13-15)$. The knowledge and attitudes of pharmacists were found to be influencing factors in promoting this generic substitution. Several previous studies also evaluated the knowledge and attitudes of pharmacists about prescribing generic drugs at both the national and international levels (3-6). Several previous studies measured the attitudes and perceptions of community pharmacists $(3-5,16)$ and other health care professionals toward generic drugs including in Saudi Arabia and other international countries $(8,13,16)$. Besides this, earlier studies among practicing health care workers, including pharmacists, concluded that generic drugs are therapeutically equivalent to their brands and effectiveness was similar to branded medicine $(4,13,17,18)$. Although data among student pharmacists found negative attitudes (14). In Yemen, a previous study by Othman and Abdulghani among pharmacy students reported negative attitudes and beliefs that generic medicines are less effective than branded medicines (14). Similarly, another study by Othman and Abdulghani reported negative perceptions of generic medicines as inferior, less effective, and produced more side effects compared with branded medicines (14). Likewise, another study among health care students from Pakistan reported positive perceptions and knowledge about prescribing generic drugs (15). In Saudi Arabia, there have been many published reports examining the attitudes of practicing pharmacists. Although studies among pharmacy students remain to be lacking. As pharmacy students represent our future pharmacists, determining their views about generic prescriptions is crucial in promoting generic drug substitution. In this study, we evaluated the knowledge and attitudes of pharmacy students, as well as other factors that may affect the selection of generic drugs.

\section{METHODS}

This study used a descriptive, cross-sectional design and was conducted at the King Saud University, college of pharmacy, among PharmD students over 3 months, from January to March 2021. The data collection was carried using self-administered questionnaires through Google Forms. The inclusion criteria included were participants who were currently enrolled in the King Saud University College of Pharmacy and students of entry levels (second and third year), who were enrolled in the study. Senior students and students from other courses and other universities in Saudi Arabia were excluded from the study.

The questionnaires for this study were prepared after an extensive review of similar studies published in other countries $(13,14)$. The First draft of the questionnaires was reviewed by the research team comprised of a professor and the researcher. The first section had 10 questions examining the knowledge of pharmacy students on generic drugs I binary answers (Yes/No). The second section of the survey contained questions concerning attitudes, which were measured using a 5-point Likert scale ranging from "strongly agree" to "strongly disagree," with a total of 14 items. The third section contained questions regarding possible barriers or factors that might influence the prescription of generic drugs in Saudi Arabia, adopted from a previous study $(13,14)$.

The questionnaires were translated into the national language using the assistance of an Arabic-speaking senior professor in the Clinical Pharmacy department and a certified Saudi Arabian translator. Before the survey questionnaires were distributed to the intended participants, a pilot study was conducted among a randomly selected group of 10 pharmacy students. The pilot study was done to test the reliability of the questionnaires. The reliability was determined using the Cronbach alpha value, which was found to be 0.71 . The results of the pilot study were not included in the main study. The validated Arabic questionnaires were then used for data collection. Social media platforms were chosen as the potential medium for data collection.

The Raosoft online calculator was used to calculate the sample size for this study (http://www.raosoft.com/samplesize.html). The sample size was calculated by assuming 300 students as the population and currently registered in the university pursuing their second and third-year courses with a confidence level of $95 \%$ and a predetermined margin of error of $5 \%$, which resulted in a sample of 169 individuals (16). We assumed that the response distribution for each question would be $50 \%$ because we are not sure what to expect the results for each question. We used $50 \%$ as the response distribution, which gave a larger sample size for this research (16).

The data were collected through online questionnaires after personally contacting the leader of the course. We created the google forms and the electronic survey link was distributed to the students. In the survey link, before answering the questionnaire, there was an introductory paragraph that talked about the objectives and importance of the study. The students were informed that their contribution was voluntary and anonymous and the students who read and agreed to the next page were redirected to research questions, considered as the consent from the student. However, this study was conducted following the guidelines of the Checklist for Reporting the Results of Internet E-Surveys (CHERRIES) (19). The ethical committees from the College of Medicine King Saud University have reviewed the questionnaires and granted permission to carry out the study. The study got institutional ethical approval from the College of Medicine, King Saud University Riyadh Saudi Arabia. 
TABLE 1 | Knowledge of Saudi PharmD students on generic medicines ( $n=193)$.

\begin{tabular}{|c|c|c|}
\hline Knowledge items & Correct (\%) & Incorrect (\%) \\
\hline $\begin{array}{l}\text { 1. A generic medicine is a drug that is sold under a different brand name or the drug's } \\
\text { non-proprietary name. }\end{array}$ & $134(70.2)$ & $57(29.8)$ \\
\hline $\begin{array}{l}\text { 2. Before they can be licensed for marketing, generic products must be bioequivalent to the } \\
\text { innovator brand. }\end{array}$ & $123(64.4)$ & $68(35.6)$ \\
\hline $\begin{array}{l}\text { 3. In nations that require bioequivalent data, product quality data are NOT necessary before a } \\
\text { generic product can be registered. }\end{array}$ & $170(89)$ & $21(11)$ \\
\hline $\begin{array}{l}\text { 4. It is thought that a generic product's efficacy, quality, and safety are comparable to the original } \\
\text { branded product if it meets bioequivalence and product quality requirements. }\end{array}$ & $123(64.4)$ & $68(35.6)$ \\
\hline $\begin{array}{l}\text { 5. Two pharmacological drugs are bioequivalent if they are pharmaceutically equivalent and their } \\
\text { bioavailability is close enough that their effects can be expected to be substantially the same in } \\
\text { terms of efficacy and safety. }\end{array}$ & $112(58.6)$ & $79(41.4)$ \\
\hline $\begin{array}{l}\text { 6. The } 90 \% \text { confidence intervals for the ratio of each pharmacokinetics parameter must be within } \\
\text { the range of } 90-110 \% \text { for a generic medicine to be bioequivalent to its innovator brand or other } \\
\text { generics. }\end{array}$ & $83(43.5)$ & $108(56.5)$ \\
\hline $\begin{array}{l}\text { 7. A generic drug is typically created without a license from the innovator business, but marketed } \\
\text { after the patent or other exclusive rights on the original medicine have expired. }\end{array}$ & $133(69.6)$ & $58(30.4)$ \\
\hline $\begin{array}{l}\text { 8. When two medicinal products are bioequivalent, the calculated Cmax and AUC ratios for each } \\
\text { formulation can differ by } 20-25 \% \text {. }\end{array}$ & $138(72.3)$ & $53(27.7)$ \\
\hline $\begin{array}{l}\text { 9. Where a "generic substitution" policy exists, community pharmacists are permitted to distribute a } \\
\text { different brand of the drug, but may or may not refer the patient back to the doctor, depending on } \\
\text { the jurisdiction/law. }\end{array}$ & $94(49.2)$ & $97(50.8)$ \\
\hline 10. If a generic drug is bioequivalent to a branded drug, it is also therapeutically equivalent. & $126(66)$ & 65 (34) \\
\hline
\end{tabular}

TABLE 2 | Possible factors influencing generic drug selection.

\begin{tabular}{lccc}
\hline Variables & $\begin{array}{c}\text { Least } \\
\text { important } \\
\text { factor } \boldsymbol{n} \text { (\%) }\end{array}$ & $\begin{array}{c}\text { Important } \\
\text { factor } \\
\boldsymbol{n} \text { (\%) }\end{array}$ & $\begin{array}{c}\text { Neutral } \\
\boldsymbol{n}(\%)\end{array}$ \\
\hline $\begin{array}{l}\text { Lack of faith in } \\
\text { generic drugs }\end{array}$ & $23(12)$ & $85(44.5)$ & $83(44.5)$ \\
$\begin{array}{l}\text { Policies, laws, } \\
\text { and regulations } \\
\text { are readily } \\
\text { available. } \\
\begin{array}{l}\text { Consequences } \\
\text { for law }\end{array}\end{array}$ & $16(8.4)$ & $133(69.6)$ & $42(22)$ \\
$\begin{array}{l}\text { Customer costs } \\
\text { are lower. }\end{array}$ & $17(8.9)$ & $126(66)$ & $48(25.1)$ \\
$\begin{array}{l}\text { No other option } \\
\text { is available. }\end{array}$ & $29(15.2)$ & $108(56.5)$ & $54(28.3)$ \\
$\begin{array}{l}\text { The appearance } \\
\text { or nationality of } \\
\text { the customer } \\
\text { Generic drugs } \\
\text { are } \\
\text { cost-effective. } \\
\begin{array}{l}\text { Confidence in } \\
\text { the product }\end{array}\end{array}$ & $115(60.2)$ & $29(15.2)$ & $47(24.6)$ \\
\hline
\end{tabular}

\section{Statistical Analysis}

The data were analyzed using SPSS Version 26 (IBM, Armonk, New York, United States) for Windows. Descriptive statistics, including percentages and frequency distribution, were calculated for each variable. For the age variable, the mean values were presented.

\section{RESULTS}

In total, 193 PharmD students self-administered the online questionnaire. The mean age of the students was $21.05 \pm(\mathrm{SD}=$ 1.03). The knowledge of generic medications among the PharmD students is shown in Table 1 . More than $70 \%$ of the students $(134 / 193,70.2 \%)$ were able to define the term generic medicine, and more than half $(123 / 193,64.4 \%)$ were able to correctly define bioequivalence. Between 89 and $65 \%$ of the surveyed students identified the requirement for the bioequivalence data, quality efficacy, and safety requirements for generic drugs, similar to the original branded products. More than half of the students (108/193, 56.5\%) lacked knowledge about the pharmacokinetic parameters of generic products; however, more than $70 \%$ of the students $(138 / 193,72.3 \%)$ agreed that when two drug products are bioequivalent, it means that the Cmax and area under the curve (AUC) ratios estimated for each formulation can vary by $20-25 \%$. Finally, most of the students $(126 / 193,66 \%)$ correctly identified that if the generic is bioequivalent to a branded medicine, it implies that it is restoratively similar.

Students reported that cheaper costs to patients $(153 / 193$, $80.1 \%)$; cost-effectiveness of generic medicines (137/193, 72\%); availability of policies, laws, and regulations (133/193, 69.6\%), and legal implications $(126 / 193,66 \%)$ were the most important factors influencing generic drug selection (Table 2).

As per our findings, the majority of students (122/193, $85 \%$ ) reported (agreed/strongly agreed) that they would support generic over brand name drugs in all cases where a generic is 
TABLE 3 | Attitudes on generic medicines utilization $(n=193)$.

\begin{tabular}{|c|c|c|c|c|c|}
\hline Variables & $\begin{array}{l}\text { Strongly } \\
\text { agree } \\
n(\%)\end{array}$ & $\begin{array}{l}\text { Agree } \\
n(\%)\end{array}$ & $\begin{array}{l}\text { Disagree } \\
n(\%)\end{array}$ & $\begin{array}{c}\text { Strongly } \\
\text { disagree } \\
n(\%)\end{array}$ & $\begin{array}{l}\text { Neutral } \\
n(\%)\end{array}$ \\
\hline $\begin{array}{l}\text { In all circumstances where a generic is available, I favor generic } \\
\text { substitutes for brand-name medications. }\end{array}$ & $45(23.6)$ & $77(40.3)$ & $9(4.7)$ & $5(2.6)$ & $55(28.8)$ \\
\hline $\begin{array}{l}\text { Less money will be spent on research and development of novel } \\
\text { drugs as generic medicines become more widely used. }\end{array}$ & $32(16.6)$ & $67(34.7)$ & $33(17.3)$ & $15(7.8)$ & $44(23)$ \\
\hline $\begin{array}{l}\text { The government of Saudi Arabia will save money on healthcare if } \\
\text { generic drugs are used more widely. }\end{array}$ & $23(11.9)$ & $52(26.9)$ & $49(25.7)$ & $12(6.2)$ & $55(28.5)$ \\
\hline $\begin{array}{l}\text { Switching a patient from a branded to a generic treatment can } \\
\text { have an impact on the drug's outcome. }\end{array}$ & $16(8.4)$ & $36(18.8)$ & $64(33.5)$ & $21(11)$ & $54(28.3)$ \\
\hline Most generic products have a high rate of therapeutic failure. & $19(9.9)$ & $43(22.5)$ & $47(24.6)$ & $20(10.5)$ & $62(32.5)$ \\
\hline $\begin{array}{l}\text { All medications approved as generic drugs by Saudi Arabia's } \\
\text { health authorities can be regarded therapeutically similar to their } \\
\text { brand-name counterparts. }\end{array}$ & $47(24.6)$ & $69(36.1)$ & $14(7.3)$ & $4(2.1)$ & $57(29.8)$ \\
\hline $\begin{array}{l}\text { Because the price difference between generic and branded drug } \\
\text { is frequently so large, I feel compelled to administer prescriptions } \\
\text { with generic replacement, especially for those who do not have } \\
\text { prescription drug coverage in Saudi Arabia. }\end{array}$ & $34(17.8)$ & $67(35.1)$ & 26 (13.6) & 7 (3.7) & 57 (29.8) \\
\hline $\begin{array}{l}\text { Patients should be given a thorough explanation of why generic } \\
\text { drugs were chosen for their therapy. }\end{array}$ & 45 (23.6) & 59 (30.9) & 14 (7.3) & 34 (17.8) & 39 (20.4) \\
\hline $\begin{array}{l}\text { When it comes to dispensing generics, the intensity of promotional } \\
\text { actions by medical representatives is crucial. }\end{array}$ & 19 (9.9) & 70 (36.6) & $9(4.7)$ & 19 (9.9) & $74(38.7)$ \\
\hline $\begin{array}{l}\text { Bioequivalence evidence should be required before a generic } \\
\text { product is marketed in Saudi Arabia, according to health officials. }\end{array}$ & $58(30.4)$ & 55 (28.8) & 5 (2.6) & 22 (11.5) & $51(26.7)$ \\
\hline $\begin{array}{l}\text { Without consulting the prescribing physician, pharmacists should } \\
\text { be able to make generic substitutions. }\end{array}$ & 32 (16.8) & 55 (28.8) & $37(19.4)$ & 20 (10.5) & 47 (24.6) \\
\hline $\begin{array}{l}\text { Pharmacists must consult with the prescribing physician before } \\
\text { beginning generic substitution. }\end{array}$ & 19 (9.9) & 56 (29.3) & $32(16.8)$ & 24 (12.6) & $60(31.4)$ \\
\hline $\begin{array}{l}\text { Only when substituting specific types of medications, such as } \\
\text { those with a limited therapeutic index, should pharmacists speak } \\
\text { with the prescribing physician. }\end{array}$ & $29(15.2)$ & 63 (33) & 23 (12) & 20 (10.5) & 56 (29.3) \\
\hline $\begin{array}{l}\text { In general, I would not provide my patients generic medications (in } \\
\text { the future, if I became a pharmacist in KSA). }\end{array}$ & $4(2.1)$ & 23 (12) & $60(31.4)$ & $28(14.7)$ & 76 (39.8) \\
\hline
\end{tabular}

available. More than half of the students $(99 / 193,66.7 \%)$ agreed that the wider use of generic medicines would mean that less money would be required for the research and development of new pharmaceuticals. Further, most students $(75 / 193,64 \%)$ have also agreed that the use of generic medicines would result in decreased healthcare expenditure by the government. When asked about therapeutic equivalence, most of the students $(116 / 193,82.7 \%)$ accepted that all products approved as generic drugs by the health authorities in the state of Saudi Arabia can be considered therapeutically equivalent to their branded counterparts; $\sim 69 \%(101 / 193)$ of the students agreed that the price difference between generic and branded drugs is often so great that they feel they should dispense prescriptions of generic substitutions, especially for people who do not have prescription drug benefits in Saudi Arabia.

When asked about the requirements of generic drugs, 113/193 $(86.4 \%)$ of the students agreed that health authorities should implement policies that bioequivalence data are mandatory before a generic product is marketed. More than half of the students $(87 / 193,60.4 \%)$ thought that pharmacists should be allowed to perform generic substitutions without consulting the prescribing physician. Slightly less than half (75/193, 48\%) agreed that they should consult physicians before prescribing generics to patients; however, about $62 \%(92 / 193)$ of the students accepted that pharmacists should be required to consult the prescribing physician when substituting certain categories of drugs with narrow therapeutic indices. The details of the attitudes of Saudi PharmD students toward generic substitutions are described in Table 3.

The most common source of information for the generic medicine among the students was social media and the internet 117 (60\%), followed by academic teacher 109 (55.9\%), printed materials and textbook 79 (40.5\%), ministry of health 72 (36.9\%), and radio or television 4 (2.7\%) (refer to Figure 1).

\section{DISCUSSION}

In this study, the responses of male pharmacy students were collected, but the female students were excluded. This is likely because of the Islamic prevalence of Saudi Arabia, where men are prohibited to interact with females and where coeducation is strictly prohibited. In this study, $\sim 65 \%$ of the students agreed 


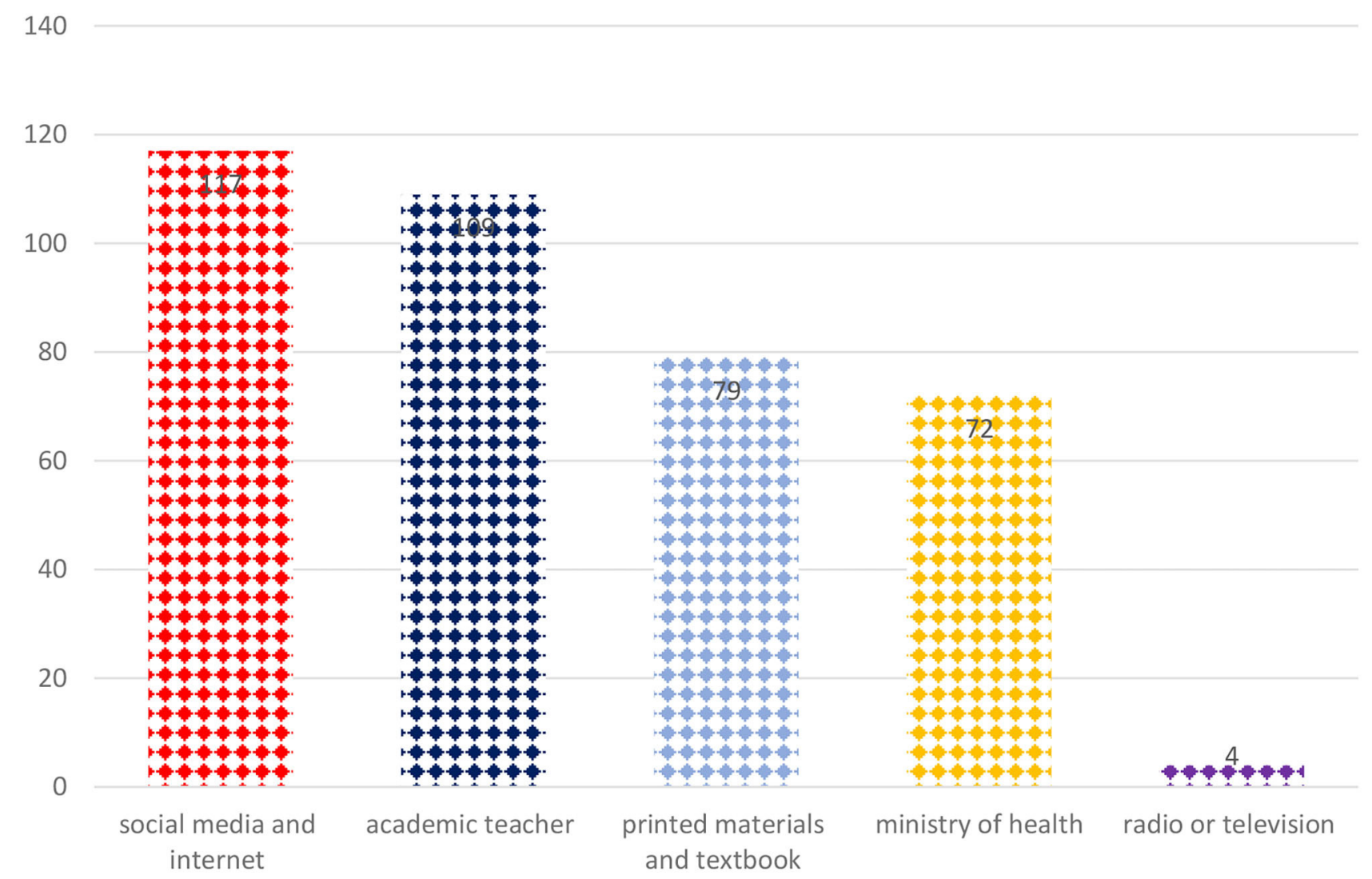

FIGURE 1 | Resources about generic medicine.

that generic products are similar in efficacy, quality, and safety compared to the original branded products. These findings were in line with earlier studies from Ethiopia (67\%) (20), but higher than the findings of James et al. (55\%) (21), Belay et al. (52.9\%) (22), Toklu et al. (46.1\%) (23), and Al Hussain et al. (42.2\%) (24). However, our results were still lower than earlier studies by Grover et al. (70\%) and Wajid et al. (72.2\%) among community pharmacists $(3,25)$. One study among Yemeni pharmacy students from private universities revealed that students perceived generic medicines to be inferior and less effective and, thus, could lead to more side effects compared with branded medicines (14). The difference in knowledge about generic medicines might be due to the fact that the majority of respondents in the current study are currently undergraduates and entry-level students with a lack of working experience or training in pharmacy settings.

Only about $44 \%$ of the students correctly answered that pharmacokinetic parameters of generic drugs must lie within 90$110 \%$ of their branded counterparts, with a $90 \% \mathrm{CI}$, which is lower than the previous study among Yemeni students (55.2\%) (14). These current findings suggested that Saudi students might have less understood the concept of bioequivalence and its limits for generic medicine. In this study, the majority of the students used social media as the source for generic medicine followed by academic teachers and printed materials. As evidenced from the current findings how prevalent internet use is among students as it is providing medical and pharmaceutical-related information very quickly at any time period, which might be the fact that students had good knowledge about generic drugs and substitution.

This study found that $85 \%$ of the students support generic substitution, while about $67 \%$ believe that generic medicines are cheaper, consistent with earlier studies published among pharmacists and pharmacy students. The majority $(80 \%)$ of students knew the definition of generic drugs, which is similar to earlier studies published among Pakistani and Yemeni students $(14,15)$. This finding suggested that most students and working pharmacists were well-informed about the prescription of generic drugs, perhaps due to various hospitals and community outlet training and rotations required before their graduation. These current study results were also consistent with those of a previous study published among pharmacy and medical students from Pakistan, which reported that both pharmacy and medical students agreed that the use of generics had the capacity to reduce pharmaceutical expenses as compared to high-priced name brand medicines (15). In our study, slightly less than half of the students agreed that prescribing generics saved costs to the government as well as to the patients. According to this study, most of the students disagreed that therapeutic failure is a serious problem with most generic products, and the majority 
of students agreed that all pharmaceuticals approved as generic drugs by the health authorities in Saudi Arabia can be considered therapeutically equivalent to their branded counterparts. These findings also revealed that students had a positive attitude toward generic drugs, which is similar to earlier studies from different countries (15).

Earlier studies suggested that the availability of generic drugs in the pharmacy was mainly due to bonuses being offered by pharmaceutical companies, which was a potential influencing factor for prescribing generics and maximizing pharmacy profits $(14,15,17)$. This earlier finding shows that pharmacists and healthcare professionals are also prone to drug promotions and, therefore, need to be trained on how to objectively evaluate drug information from the manufacturers $(14,15,17)$.

In this study, students identified that having the cheapest cost to patients; cost-effectiveness of generic medicines; availability of policies, regulations, legal implications; and having no other choices were potential influencing factors in generic drug selection. However, earlier studies found that to improve the awareness and promote the prescription of generic drugs in the public healthcare system, there is a need to publicize the quality control tests of generic drugs, which were similar to the quality of branded medicines (26). Furthermore, educational interventions were most beneficial in improving the knowledge of generic drugs among students and practicing pharmacists, as reported by Almangour et al. (27). In addition to this, allocation of financial sources and good patient-healthcare professional communication can create a positive impact of generic medicines in the minds of patients and the healthcare system. Although the current had some limitations, first this study is limited to only male pharmacy students, from a single institution, therefore the results cannot be generalizable to the whole of Saudi Arabia. Second, the study included junior-level students who are currently in their second and third year of the PharmD course. The cross-sectional nature of the study, could not be able to find out the factors affecting the generic medicine knowledge. We recommend that further studies among pharmacy students with a larger sample size are needed to create awareness and to

\section{REFERENCES}

1. Barlas S. Are hospital prices a bigger problem than drug prices? Congress doesn't know, doesn't care. Pharm Ther. (2019) 44:259-99.

2. Health Affairs: Rising Cost of Drugs: Where Do We Go From Here. Available online at: https://www.healthaffairs.org/do/10.1377/hblog20150831.050265/ full/ (assessed March 23, 2021).

3. Wajid S, Al-Arifi M, Al Nomay H, Al Mousa YN, Babelghaith SD. Knowledge and perception of community pharmacists' towards generic medicines in Saudi Arabia. Biomed Res. (2015) 26:800-6.

4. Shraim NY, Al Taha TA, Qawasmeh RF, Jarrar HN, Shtaya MA, Shayeb LA, et al. Knowledge, attitudes and practices of community pharmacists on generic medicines in Palestine: a cross-sectional study. BMC Health Serv Res. (2017) 17:847. doi: 10.1186/s12913-017-2813-z

5. Awaisu A, Kheir N, Ibrahim MI, El-Hajj M, Hazi H, Khudair N, et al. Knowledge, attitudes, and practices of community pharmacists on generic medicines in Qatar. Int J Clin Pharm. (2014) 36:394404. doi: 10.1007/s11096-013-9909-2 improve the knowledge toward generic medicine in Saudi Arabia and other countries are needed.

\section{CONCLUSION}

This present study identifies that junior Pharm D students from a single university in Saudi Arabia had acceptable knowledge with respect to generic medicines. The matter of generic medicine cost and quality need to be made a focus for students lacking adequate knowledge in some aspects of the pharmacokinetics of generic medicines. Educational intervention and development of policies by healthcare government officials can improve the practice of generic medicine substitution in Saudi Arabia.

\section{DATA AVAILABILITY STATEMENT}

The raw data supporting the conclusions of this article will be made available by the authors, without undue reservation.

\section{ETHICS STATEMENT}

Ethical Committees from College of Medicine, King Saud University was reviewed the questionnaires and granted permission to carry out the study, study got institutional ethical approval from College of Medicine, King Saud University, Riyadh, Saudi Arabia. The patients/participants provided their written informed consent to participate in this study.

\section{AUTHOR CONTRIBUTIONS}

The author confirms being the sole contributor of this work and has approved it for publication.

\section{ACKNOWLEDGMENTS}

The authors of this study extend their appreciation to Researcher Supporting Project (project number RSP-2021/81), King Saud University, Saudi Arabia.
6. Alghasham AA. Generic drug prescribing in central Saudi Arabia: perceptions and attitudes of physicians. Ann Saudi Med. (2009) 29:249. doi: 10.4103/0256-4947.51819

7. USFDA. Generic Drugs Facts. Available online at: https://www.fda.gov/drugs/ generic-drugs/generic-drug-facts (accessed April 4, 2021).

8. Al-Worafi YM, Alseragi WM, Alakhali KM, Ming LC, Othman G, Halboup $\mathrm{AM}$, et al. Knowledge, beliefs and factors affecting the use of generic medicines among patients in Ibb, Yemen: a mixed-method study. Age. (2020) 10:3-12. doi: $10.5530 / j p p c m .2020 .4 .16$

9. The-Global-Use-Of-Medicine-in-2019-and-Outlook-to2023- (By IQVIA) (Page2\#). Available online at: https://www.iqvia.com/insights/the-iqviainstitute/reports/the-global-use- of-medicine-in-2019-and-outlook-to-2023 (accessed April 4, 2021).

10. The Rising Burden of Medication in KSA. A Pragmatic Approach to Minimize It. Available online at: https://apps.who.int/medicinedocs/en/m/ abstract/Js21608en/ (accessed April 4, 2021).

11. Alrasheedy AA, Hassali MA, Wong ZY, Aljadhey H, Al-Tamimi SK, Saleem F. Pharmaceutical policy in Saudi Arabia. In: Babar ZUD, editor. Pharmaceutical 
Policy in Countries With Developing Healthcare Systems. Springer (2017). p. 329-47.

12. Fitch Solutions Group. Saudi Arabia Pharmaceuticals \& Healthcare Report. Middle East and North Africa (2019).

13. Chua GN, Hassali MA, Shafie AA, Awaisu A. A survey exploring knowledge and perceptions of general practitioners towards the use of generic medicines in the northern state of Malaysia. Health Policy. (2010) 95:22935. doi: 10.1016/j.healthpol.2009.11.019

14. Othman GQ, Abdulghani MA. Assessment of knowledge and perceptions of generic medicines among pharmacy students in Yemeni universities. Pharm Educ. (2015) 15.

15. Asif U, Saleem Z, Yousaf M, Saeed H, Hashmi FK, Hassali MA. Exploring the knowledge and attitude of medical and pharmacy students about generic medicine in Lahore, Pakistan. J Generic Med. (2018) 14:228. doi: 10.1177/1741134317748344

16. Raosoft. Sample Size Calculator. (2020). Available online at: http://www. raosoft.com/samplesize.html (accessed September 17, 2020).

17. Abanmi M, Alghamdi A. exploring the knowledge and perception of generic medicine use among community pharmacists in Saudi Arabia. Value Health. (2018) 21:S158. doi: 10.1016/j.jval.2018.09.939

18. Salhia HO, Ali A, Rezk NL, El Metwally A. Perception and attitude of physicians toward local generic medicines in Saudi Arabia: a questionnaire-based study. Saudi Pharm J. (2015) 23:397-404. doi: 10.1016/j.jsps.2015.01.014

19. Eysenbach G. Correction: improving the Quality of web surveys: the checklist for reporting results of internet E-Surveys (CHERRIES). J Med Internet Res. (2012) 14:e8. doi: 10.2196/jmir.2042

20. Mohammed AS, Woldekidan NA, Mohammed FA. Knowledge, attitude, and practice of pharmacy professionals on generic medicines in Eastern Ethiopia: a cross-sectional study. PLOS ONE. (2020) 15:e0235205. doi: 10.1371/journal.pone.0235205

21. James PB, Bah AJ, Margao EK, Hanson C, Kabba JA, Jamshed SQ. Exploring the knowledge and perception of generic medicines among final year undergraduate medical, pharmacy, and nursing students in Sierra Leone: a comparative cross-sectional approach. Pharmacy. (2018) 6:3. doi: 10.3390/pharmacy6010003

22. Belay YB, Kassa TT, Teni FS, Dinkashe FT, Kassa AG, Welie AG. Assessment of knowledge, attitude and practice of pharmacy professionals toward generic medicines, Northern Ethiopia, Mekelle: a cross sectional study. J Basic Clin Pharm. (2017) 8:193-9.
23. Toklu HZ, Dülger GA, Hidiroglu S, Akici A, Yetim A, Gannemoglu $\mathrm{HM}$, et al. Knowledge and attitudes of the pharmacists, prescribers and patients towards generic drug use in Istanbul-Turkey. Pharm Prac. (2012) 10:199. doi: 10.4321/S1886-365520120004 00004

24. Al Hussaini M, Alsaffar N, Abdulraheem A. Exploring community pharmacists' knowledge, perception and experiences towards branded and generic medicines in Kuwait: highlighting the role of pharmacist. Bull Facul Pharm Cairo Univ. (2018) 56:109-14. doi: 10.1016/j.bfopcu.2018. 03.005

25. Grover P, Stewart J, Hogg M, Short L, Seo HG, Rew A. Evaluating pharmacists' views, knowledge, and perception regarding generic medicines in New Zealand. Res Soc Administr Pharm. (2011) 7:294-305. doi: 10.1016/j.sapharm.2010.06.004

26. Singal G, Nanda A, Kotwani A. A comparative evaluation of price and quality of some branded versus branded-generic medicines of the same manufacturer in India. Indian J Pharmacol. (2011) 43:131-6. doi: 10.4103/0253-7613. 77344

27. Almangour TA, Wajid S, Alghadeer S, Alhossan AA, Babelghaith SD, AlArifi MN. Influence of continuing education program on pharmacy students' knowledge about generic drugs in Saudi Arabia. J Young Pharmacists. (2021). 13:72. doi: 10.5530/jyp.2021.13.16

Conflict of Interest: The author declares that the research was conducted in the absence of any commercial or financial relationships that could be construed as a potential conflict of interest.

Publisher's Note: All claims expressed in this article are solely those of the authors and do not necessarily represent those of their affiliated organizations, or those of the publisher, the editors and the reviewers. Any product that may be evaluated in this article, or claim that may be made by its manufacturer, is not guaranteed or endorsed by the publisher.

Copyright (C) 2021 Al-Arifi. This is an open-access article distributed under the terms of the Creative Commons Attribution License (CC BY). The use, distribution or reproduction in other forums is permitted, provided the original author(s) and the copyright owner(s) are credited and that the original publication in this journal is cited, in accordance with accepted academic practice. No use, distribution or reproduction is permitted which does not comply with these terms. 